\title{
Effect of fathers' age and birth order on occurrence of congenital heart disease
}

A case-control analysis studying the effect of paternal age and parity on the occurrence of congenital heart disease was recently reported. ${ }^{1}$ The study was based on 497 cases aged between 3 months and 5 years, born in Beijing and Hebei Province, China. The control population was made up of two groups: 222 infants resident in Beijing or Hebei and treated in hospitals, and community controls: 6000 infants born in Beijing or one region of Hebei Province. When studying the effect of father's age on heart defects, the authors found a Mantel-Haenszel odds ratio of 2.63 for $<25$ years (after controlling for birth order) with a $95 \%$ confidence interval $(95 \% \mathrm{CI})$ of $2 \cdot 12-3 \cdot 27$. Similar findings were obtained when controlling for maternal age but data were not shown.

We report here a Swedish case-control study in which we investigated the possible effect of paternal age on the occurrence of congenital heart disease. The effects of maternal age and parity have been discussed in a previous paper. ${ }^{2}$ Cases are all infants born in 1985-1986 in Sweden and presenting a major congenital heart defect, usually diagnosed by echocardiography, cardiac catheterisation, at operation, or at necropsy. These infants were identified from two Swedish registries: the Registry of Congenital Malformations ${ }^{3}$ and the Child Cardiology Registry. Cases with a known chromosomal anomaly have been excluded from the material. Two sets of controls were used: a group of 776 infants randomly selected from the Medical Birth

Effect of paternal age on the occurence of congenital heart disease (CHD). For all CHD as a group, the odds ratios, calculated by Mantel-Haenszel technique after stratification for maternal age and parity, are given with their $95 \%$ confidence intervals (95\% CI). Observed/expected rates calculated from all births in 1985-1986 and after standardisation for maternal age are also given for all CHD and for two types of CHD: truncus anomalies and septal defects (without other cardiac defects). types of CHD: truncus anomalies and septal defects without other cardiac defect
When the number of cases was less than 10, the exact $95 \%$ CI was obtained from Poisson distributions.

\begin{tabular}{|c|c|c|c|c|c|c|}
\hline & \multicolumn{6}{|c|}{ Paternal age (years) } \\
\hline & $<25$ & $25-29$ & $30-34$ & $35-39$ & $40-44$ & $>44$ \\
\hline $\begin{array}{l}\text { Number of cases } \\
\text { Number of controls } \\
\text { Odds ratio } \\
95 \% \text { CI } \\
\text { Observed/expected } \\
95 \% \text { CI }\end{array}$ & $\begin{array}{l}34 \\
79 \\
0.92 \\
0.56-1.49 \\
0.89 \\
0.64-1.25\end{array}$ & $\begin{array}{l}119 \\
233 \\
1 \cdot 11 \\
0.83-1 \cdot 50 \\
1.04 \\
0.87-1.24\end{array}$ & $\begin{array}{l}131 \quad A l \\
264 \\
1.01 \\
0.77-1.33 \\
1 \cdot 06 \\
0.89-1.25\end{array}$ & $\begin{array}{c}C H D \\
65 \\
138 \\
0 \cdot 92 \\
0 \cdot 65-1 \cdot 32 \\
0 \cdot 89 \\
0 \cdot 70-1 \cdot 14\end{array}$ & $\begin{array}{l}24 \\
53 \\
0.82 \\
0.48-1 \cdot 39 \\
1.03 \\
0.69-1.53\end{array}$ & $\begin{array}{l}7 \\
9 \\
1.52 \\
0.57-4.06 \\
0.98 \\
0.39-2.01\end{array}$ \\
\hline $\begin{array}{l}\text { Number of cases } \\
\text { Observed/expected } \\
95 \% \text { CI }\end{array}$ & $\begin{array}{l}13 \\
0.91 \\
0.53-1.57\end{array}$ & $\begin{array}{c}43 \\
1 \cdot 04 \\
0 \cdot 77-1 \cdot 40\end{array}$ & $\begin{array}{c}\text { Trunce } \\
47 \cdot 14 \\
1.86-1.52\end{array}$ & $\begin{array}{c}\text { anomalies } \\
18 \\
0.80 \\
0.50-1.26\end{array}$ & $\begin{array}{l}6 \\
0.84 \\
0.31-1.83\end{array}$ & $\begin{array}{l}2 \\
0.92 \\
0.11-3.33\end{array}$ \\
\hline $\begin{array}{l}\text { Number of cases } \\
\text { Observed/expected } \\
95 \% \mathrm{CI}\end{array}$ & $\begin{array}{l}5 \\
0.90 \\
0 \cdot 29-2.09\end{array}$ & $\begin{array}{c}16 \\
0.84 \\
0.51-1.37\end{array}$ & $\begin{array}{l}\quad{ }^{\quad S e p t} \\
1 \cdot 14 \\
0 \cdot 77-1 \cdot 69\end{array}$ & $\begin{array}{c}\text { al defects } \\
12.93 \\
0.53-1.64\end{array}$ & $\begin{array}{l}4 \\
0.95 \\
0 \cdot 26-2 \cdot 42\end{array}$ & $\begin{array}{l}3 \\
2 \cdot 27 \\
0.47-6.64\end{array}$ \\
\hline Number of births & 18492 & 54549 & 55814 & 30731 & 10038 & 3216 \\
\hline
\end{tabular}

Registry among all infants born in the same year at the same delivery unit as the cases, ${ }^{5}$ and all births in 1985-1986, that is 172840 infants.

We first studied the possible effect of paternal age on the occurrence of congenital heart disease, stratifying for maternal age and parity. The table gives for each paternal age class the number of cases and controls and the odds ratio with its $95 \%$ confidence interval. No paternal age effect is observed. In each class, the odds ratio is very close to 1, except for fathers older than 44 years $(O R=1.52, C I 0.57-4.06)$ but the number of cases and controls is very small (7 and 9, respectively). Using all births in 1985-1986 as a control group, the possible effect of paternal age after standardisation for maternal age was studied for all cardiac defects and for two large groups of defects: truncus anomalies and septal defects. Only cases without other cardiac anomalies were included. These two types of congenital heart disease are part of a classification described elsewhere. ${ }^{2}$ The table summarises the results. No effect is observed.

Few studies on the possible effect of paternal age on the occurrence of congenital heart disease have been reported. If such an effect exists, the biological mechanism involved is difficult to understand. In this study, no association appears between paternal age and congenital heart disease and, as Zhan et al suggested, the results of their study could be biased. ${ }^{1}$ Although it is reasonable to think that no effect exists, more studies are needed to determine the possible role of the age of the father on the occurrence of congenital heart defects.

PIERRE PRADAT Department of Embryology Biskopsgatan 7 S-223 62 Lund Sweden

1 Zhan SY, Lian AH, Zheng DZ, Gao L. Effect of fathers' age and birt disease. $f$ and birth order on occurrence of congenital heart

2 Pradat P. The epidemiology of major congenital heart Pradat P. The epidemiology of major congenital heart defects in Sweden, 1981 3 Källén B, Winberg J. A Swedish register of congenital malformations. Experience with continuous registration during 2 years with special reference to multiple malformations. Pediatrics 1968; 41: 765-76.

4 Carlgren L-E, Ericson A, Källén B. Monitoring of congenital cardiac defects. Pediatr Cardiol 1987; 8: 247-56. 5 Cnattingius S, Ericson A, Gunnarskog J, Källén B. A quality study of a medical birth registry. Scand F Soc Med 1990; 18 143-8. 